\title{
The Mersenne Meet Matrices on A -Sets
}

\author{
N. Elumalai ${ }^{1}$, R. Kalpana ${ }^{2 *}$ \\ ${ }^{1}$ Dept. of Mathematics, A.V.C.College (Autonomous) ,Mannampandal - 609 305, Mayiladuthurai, India \\ ${ }^{2}$ Dept. of Mathematics, Saradha Gangadharan College, Puducherry-605 004,India \\ Corresponding Author : mathkalpana@gmail.com
}

Available online at: www.isroset.org

Accepted 18/Aug/2018, Online 30/Aug/2018

\begin{abstract}
A recursive structure theorem for Mersenne meet matrices on $A$-sets is verified and a recursive formula for det (Mersenne meet matrix) and for inverse of (Mersenne meet matrix) on $A$-sets is also verified. The recursive formulae also yield explicit formulae, e.g. the known determinant and inverse formulae on chains and $a$-sets.
\end{abstract}

Key words - Meet Matrices, Mersenne Meet Matrices, a-Set, A-Set

\section{INTRODUCTION}

Let $(\mathrm{P}, \leq)=\left(\mathrm{P}, \vee, \wedge_{-}\right)$be a locally finite lattice, let $S=\left(\mathrm{x}_{1}, \mathrm{x}_{2}, \ldots \ldots \ldots \ldots \mathrm{x}_{\mathrm{n}}\right\}$ be a subset of $P$ and let $f: P \rightarrow \mathbf{C}$ be a function. The meet matrix $(S)_{f}$ on $S$ with respect to $f$ are defined as $\left((S)_{f}\right)_{i j}=f\left(x_{i} \wedge x_{j}\right)$.

Haukkanen [1] introduced meet matrices $(\mathrm{S})_{f}$ and obtained formulae for $\operatorname{det}\left(S_{f}\right.$ and $\left(\mathrm{S}_{f}\right)^{-1}$ (see also [2] and [3]). Korkee and Haukkanen [4] used incidence functions in the study of meet matrices. There we obtained new upper and lower bounds for $\operatorname{det}(S)_{f}$ and a new formula for $\left(\mathrm{S}_{f}\right)^{-1}$ on meet-closed sets $S$ (i.e., $x_{i}, x_{j} \in S \Rightarrow x_{i} \wedge x_{j} \in S$ ). Korkee and Haukkanen [5] presented a new method for calculating $\operatorname{det}(S)_{f}$ and $\left(\mathrm{S}_{f}\right)^{-1}$ on those sets $S$ which are not necessarily meet-closed.

$S$ is an $\boldsymbol{A}$-set if the set $A=\left\{x_{i} \wedge x_{j} / x_{i} \neq x_{j}\right\}$ is a chain (an $A$-set need not be meet-closed). For example, chains and $a$ sets (with $A=\{a\}$ )are known trivial $A$ sets. Since the method, presented in [5], adapted to $A$-sets might not be sufficiently effective, we give a new structure theorem for $(S)_{f}$ where $S$ is an $A$-set. One of its features is that it supports recursive function calls.By the structure theorem we obtain a recursive formula for $\operatorname{det}(S)_{f}$ and for $\left(\mathrm{S}_{f}\right)^{-1}$ on $A$-sets[6]. By dissolving the recursion on certain sets the known explicit determinant and inverse formulae on chains and $a$-sets are obtained.

Note that $(\mathbf{Z}+, \mid)=(\mathbf{Z}+, \operatorname{gcd}, 1 \mathrm{~cm})$ is a locally finite lattice, where $\mid$ is the usual divisibility relation and gcd and $\mathrm{lcm}$ stand for the greatest common divisor and the least common multiple of integers. Thus meet matrices are generalizations of GCD matrices
$\left((S)_{f}\right)_{i j}=f\left(\operatorname{gcd}\left(x_{i}, x_{j}\right)\right)$ and therefore the results in this paper also hold for GCD. For general accounts of GCD matrices, see [8]. Meet matrices are also generalizations of GCUD matrices, the unitary analogies of GCD matrices, see [9]. Thus the results also hold for GCUD matrices.

Section I gives the introduction of meet matix and A-set, Section II elaborates the definitions of a-set,A-set and Meet matrix, Section III discusses about the structure theorem, $\operatorname{det}($ Mersenne meet matrix on A-set) and inverse (Mersenne meet matrix on A-set) and Section IV concludes the paper with the a discussion on the work carried out in this paper.

\section{DEFINITIONS}

Let $(P,<)=(P, \wedge)$ be a meet-semilattice and let $S$ be a nonempty subset of $P . S$ is meet-closed if $\mathrm{x} \wedge \mathrm{y} \in \mathrm{S}$ whenever $\mathrm{x}, \mathrm{y} \in \mathrm{S}$. $S$ is lower-closed if $(x \in S ; y \leq x) \Rightarrow y \in S$ holds for every $y \in P$. It is clear that a lower-closed set is always meet-closed but the converse is not true. The method used requires that the elements of $S$ are arranged analogously to the elements of chain $A$.

Definition 2.1 The binary operation $\Pi$ is defined by

$S_{1} \sqcap S_{2}=\left[x \wedge y / x \in S_{1}, y \in S_{2}, x \neq y\right\}$

where $S_{1}$ and $S_{2}$ are nonempty subsets of $P$.

Let $S$ be a subset of $P$ and let $a \in P$. If $S \sqcap S=\{a\}$, then the set $S$ is said to be an a-set.

Definition 2.2 Let $S=\left\{\mathrm{x}_{1}, \mathrm{x}_{2}, \ldots \ldots \ldots \ldots \mathrm{x}_{\mathrm{n}}\right\}$ be a subset of $P$ with $x_{i}<x_{j} \Rightarrow i<j$ and let

$A=\left\{\mathrm{a}_{1}, \mathrm{a}_{2}, \ldots \ldots \ldots \ldots \mathrm{a}_{\mathrm{n}-1}\right\}$ be a multichain (i.e. a chain where duplicates are allowed) with

$a_{1} \leq a_{2} \leq \ldots \ldots \ldots . \leq a_{n-1}$. The set $S$ is said to be an

A-set if $\left\{x_{k}\right\} \sqcap\left\{x_{k+1}, \ldots \ldots ., x_{n}\right\}=\left\{a_{k}\right\}$ for all 
$k=1,2, \ldots \ldots, n-1$.

Every chain $S=\left\{\mathrm{x}_{1}, \mathrm{x}_{2}, \ldots \ldots \ldots \ldots \mathrm{x}_{\mathrm{n}}\right\}$ is an $A$-set with $A=$ $S \backslash\left\{x_{n}\right\}$ and every $a$-set is always an $A$-set with $A=\{a\}$.

Definition 2.3 Let $f$ be a complex-valued function on $P$. Then the $n \times n$ matrix $(S)_{f}$, where

$\left((S)_{f}\right)_{i j}=f\left(x_{i} \wedge x_{j}\right)$, is called the meet matrix on $S$ with respect to $f$. Also the $n \times n$ matrix $(S)_{f}$, where $\left((S)_{f}\right)_{i j}=f\left(x_{i} \wedge\right.$ $\left.x_{j}\right)=2^{x_{i} \wedge x_{j}}-1$, is called the Mersenne meet matrix.

In what follows, let $S=\left\{\mathrm{x}_{1}, \mathrm{x}_{2}, \ldots \ldots \ldots \ldots \mathrm{x}_{\mathrm{n}}\right\}$ always be a finite subset of $P$ with $x_{i}<x_{j} \Rightarrow i<j$. Let also

$A=\left\{\mathrm{a}_{1}, \mathrm{a}_{2}, \ldots \ldots \ldots \ldots \mathrm{a}_{\mathrm{n}-1}\right\}$ with $a_{i}<a_{j} \Rightarrow i<j$. Note that $S$ has always $n$ distinct elements, but it is possible that the set $A$ is a multiset. Let $f$ be a complex-valued function on $P$.

\section{MERSENNE MEET MATRICES ON $A$-SETS}

\subsection{Structure Theorem}

Theorem 3.1 (Structure Theorem) Let $S=\left\{\mathrm{x}_{1}\right.$, $\left.\mathrm{x}_{2}, \ldots \ldots \ldots \ldots \mathrm{x}_{\mathrm{n}}\right\}$ be an A-set, where

$A=\left\{\mathrm{a}_{1}, \mathrm{a}_{2}, \ldots \ldots \ldots \ldots \mathrm{a}_{\mathrm{n}-1}\right\}$ is a multichain. Let $f_{1}, f_{2, \ldots \ldots . . .} f_{n}$ denote the functions on $P$ defined by

$f_{1}=f$ and

$$
f_{k+1}(x)=f_{k}(x)-\frac{f_{k}\left(a_{k}\right)^{2}}{f_{k}\left(x_{k}\right)}
$$

for $k=1,2, \ldots \ldots \ldots, n-1$.

Then $(S)_{f}=M^{T} D M$,

where $D=\operatorname{diag}\left(f_{1}\left(x_{1}\right), f_{2}\left(x_{2}\right), \ldots \ldots \ldots, f_{n}\left(x_{n}\right)\right)$ and $M$ is the $n \times$ $n$ upper triangular matrix with 1 's on its main diagonal, and further

$$
(M)_{i j}=\frac{f_{i}\left(a_{i}\right)}{f_{i}\left(x_{i}\right)}
$$

for all $i<j$. (Note that $f_{1}, \ldots \ldots \ldots, f_{n}$ exist if and only if $\left(f_{k}\left(x_{k}\right)\right.$ $\left.=0, a_{k} \neq x_{k}\right) \Rightarrow f_{k}\left(a_{k}\right)=0$ holds for all

$k=1,2, \ldots \ldots . ., n-1$. In the case $f_{k}\left(a_{k}\right)=f_{k}\left(x_{k}\right)=0,(M)_{k j}=0$ for all $k<j$.

Proof: $\quad$ Let $i<j$. Then

$$
\left(M^{\mathrm{T}} D M\right)_{i j}=\sum_{k=1}^{n}(M)_{k i}(D)_{k k}(M)_{k j}
$$

$$
\begin{aligned}
& =f_{i}\left(a_{i}\right)+\sum_{k=1}^{i-1} \frac{f_{k}\left(a_{k}\right)^{2}}{f_{k}\left(x_{k}\right)} \\
& =f_{i}\left(a_{i}\right)+\sum_{k=1}^{i-1}\left(f_{k}\left(a_{i}\right)-f_{k+1}\left(a_{i}\right)\right) \\
& =f_{1}\left(a_{i}\right)=f\left(x_{i} \wedge x_{j}\right) .
\end{aligned}
$$

The case $i=j$ is similar, we only replace every $a_{i}$ with $x_{i}$ in (3.4). Since $M^{\mathrm{T}} D M$ is symmetric, we do not need to treat the case $i>j$.

\subsection{Determinant of Meet matrix on $A$-sets}

By Structure Theorem we obtain a new recursive formula for $\operatorname{det}(S)_{f}$ on $A$-sets.

Theorem 3.2 Let $S=\left\{\mathrm{x}_{1}, \mathrm{x}_{2}, \ldots \ldots \ldots \ldots \mathrm{x}_{\mathrm{n}}\right\}$ be an A-set, where $A=\left\{\mathrm{a}_{1}, \mathrm{a}_{2}, \ldots \ldots \ldots \ldots \mathrm{a}_{\mathrm{n}-1}\right\}$ is a multichain. Let $f_{1}$, $f_{2, \ldots \ldots . . ., f_{n}}$ be the functions defined in (3.1). Then

$$
\operatorname{det}(S)_{f}=f_{1}\left(x_{1}\right) f_{2}\left(x_{2}\right) \ldots \ldots \ldots f_{n}\left(x_{n}\right),
$$

By Theorem 3.2 we obtain a known explicit formula for $\operatorname{det}(S)_{f}$ on chains presented in $[4$, Corollary 3$]$ and [14, Corollary 1].

Corollary 3.1 If $S=\left\{\mathrm{x}_{1}, \mathrm{x}_{2}, \ldots \ldots \ldots . . . \mathrm{x}_{\mathrm{n}}\right\}$ is a chain, then $\operatorname{Det}(S)_{f}=f\left(x_{1}\right) \quad \prod_{k=2}^{n}\left(f\left(x_{k}\right)-f\left(x_{k-1}\right) \quad\right.$ (3.6)

Proof: By Theorem 3.2 we have $\operatorname{det}(S)_{f}=f_{1}\left(x_{1}\right) f_{2}\left(x_{2}\right) \ldots \ldots \ldots f_{n}\left(x_{n}\right)$, where $f_{1}=f$ and $f_{k+1}(x)=f_{k}(x)-f_{k}\left(x_{k}\right)=f(x)-f\left(x_{k}\right)$ for all $k=1,2, \ldots \ldots \ldots \ldots \ldots, n-1$. This completes the proof.

By Theorem 3.2 we also obtain a known explicit formula for $\operatorname{det}(S)_{f}$ on $a$-sets. This formula has been presented (with different notation) in [1, Corollary of Theorem 3] and [5,Corollaries 5.1 and 5.2], and also in [7, Theorem 3] in number-theoretic setting.

The case $f(a)=0$ is trivial, since then $(S)_{f}=\operatorname{diag}\left(f\left(x_{1}\right)\right.$, $\left.f\left(x_{2}\right), \ldots \ldots ., f\left(x_{n}\right)\right)$ and $\operatorname{det}(S)_{f}=f\left(x_{1}\right) f\left(x_{2}\right) \ldots \ldots f\left(x_{n}\right)$.

Corollary 3.2 Let $S=\left\{\mathrm{x}_{1}, \mathrm{x}_{2}, \ldots \ldots \ldots \ldots \mathrm{x}_{\mathrm{n}}\right\}$ be an a-set, where $f(a) \neq 0$. If $a \in S$ (i.e. $\left.a=x_{1}\right)$, Then $\operatorname{det}(S)_{f}=f(a)\left(f\left(x_{2}\right)-f(a)\right) \ldots\left(f\left(x_{n}\right)-f(a)\right)$.

If $a \notin S$, then

$$
\begin{array}{r}
\operatorname{det}(S)_{f}=\sum_{k=1}^{n} \frac{f(a)\left(f\left(x_{1}\right)-f(a)\right) \ldots .\left(f\left(x_{n}\right)-f(a)\right)}{f\left(x_{k}\right)-f(a)} \\
+\left(f\left(x_{1}\right)-f(a)\right) \ldots\left(f\left(x_{n}\right)-f(a)\right) .
\end{array}
$$

Example 3.1 Let $(P, \leq \cdot)=(\mathbf{Z}+, \mid)$ and $S=\{2,3,5\}$.

Then $S=\left[\begin{array}{lll}2^{2}-1 & 2^{1}-1 & 2^{1}-1 \\ 2^{1}-1 & 2^{3}-1 & 2^{1}-1 \\ 2^{1}-1 & 2^{1}-1 & 2^{5}-1\end{array}\right]$ Since $S$ is an $A$-set with the chain $A=\{1,1\}$ by (3.1) we have $f_{1}=f, f_{2}(x)=f_{1}(x)$ $-f_{1}(1)^{2} / f_{1}(2)$ and $f_{3}(x)=f_{2}(x)-f_{2}(1)^{2} / f_{2}(3)$. and. Let $f(x)=2^{\mathrm{x}}$ 1. Then

$f_{1}(x)=2^{\mathrm{x}}-1, f_{2}(x)=2^{\mathrm{x}}-4 / 3, \quad f_{3}(x)=2^{\mathrm{x}}-7 / 5$

and by Theorem $3.1 \quad(S)_{f}=\mathrm{M}^{\mathrm{T}} \mathrm{DM}$, where $\mathrm{D}=\operatorname{diag}(3,20 / 3,153 / 5)$ and $\mathrm{M}=\left[\begin{array}{ccc}1 & 1 / 3 & 1 / 3 \\ 0 & 1 & 1 / 10 \\ 0 & 0 & 1\end{array}\right]$

and by Theorem 3.2 we have

$$
\operatorname{det}(S)_{f}=f_{1}(2) f_{2}(3) f_{3}(5)=3(20 / 3)(153 / 5)=612 \text {. }
$$

\subsection{Inverse of Mersenne meet matrix on $A$-sets}

By Structure Theorem we obtain a new recursive formula for $\left(S_{f}\right)^{-1}$ on $A$-sets.

Theorem 3.3 Let $S=\left\{\mathrm{x}_{1}, \mathrm{x}_{2}, \ldots \ldots \ldots \ldots \mathrm{x}_{\mathrm{n}}\right\}$ be an $A$-set, where $A=\left\{\mathrm{a}_{1}, \mathrm{a}_{2}, \ldots \ldots \ldots \ldots \mathrm{a}_{\mathrm{n}-1}\right\}$ is a multichain. Let $f_{1}, f_{2}, \ldots \ldots, f_{n}$ be the functions defined in (3.1), where $f_{i}\left(x_{i}\right) \neq 0$ for $i=1,2, \ldots, n$. Then $(S)_{f}$ is invertible and

$$
\left(S_{f}\right)^{-1}=N \Delta N^{\mathrm{T}}
$$


where $\Delta=\operatorname{diag}\left(1 / f_{1}\left(\mathrm{x}_{1}\right), 1 / f_{2}\left(\mathrm{x}_{2}\right), \ldots, 1 / f_{n}\left(x_{n}\right)\right)$ and $N$ is the $n \times n$ upper triangular matrix with 1 's on its main diagonal, and further

$$
(N)_{i j}=-\frac{f_{i}\left(a_{i}\right)}{f_{i}\left(x_{i}\right)} \prod_{k=i+1}^{j-1}\left(1-\frac{f_{k}\left(a_{k}\right)}{f_{k}\left(x_{k}\right)}\right)
$$

for all $i<j$.

Proof: $\quad$ By Structure Theorem $(S)_{f}=M^{\mathrm{T}} D M$, where $M$ is the matrix defined in (3.3) and

$D=\operatorname{diag}\left(f_{1}\left(x_{1}\right), f_{2}\left(x_{2}\right), \ldots \ldots, f_{n}\left(x_{n}\right)\right)$. Therefore $\quad\left(S_{f}\right)^{-1}=$ $N \Delta N^{\mathrm{T}}$,

where $\mathrm{D}^{-1}=\operatorname{diag}\left(1 / f_{1}\left(\mathrm{x}_{1}\right), 1 / f_{2}\left(\mathrm{x}_{2}\right), \ldots, 1 / f_{n}\left(x_{n}\right)\right)$ and $M^{-1}=N$ is the $n \times n$ upper triangular matrix in 3.10.

\section{Example 3.1.1}

$\mathrm{S}$ is considered the same as in Example 3.1 then by $\left(S_{f}\right)^{-1}$ $=N \Delta N^{\mathrm{T}}$,

$$
\begin{gathered}
\Delta=\operatorname{diag}(1 / 3,1 /(20 / 3), 1 /(153 / 5)), \quad \mathrm{N}=\mathrm{M}^{-1}, \\
\mathrm{~N}=\left[\begin{array}{ccc}
1 & -1 / 3 & -3 / 10 \\
0 & 1 & -1 / 10 \\
0 & 0 & 1
\end{array}\right], \\
\left(S_{f}\right)^{-1}=\left[\begin{array}{ccc}
6 / 17 & -5 / 102 & -1 / 102 \\
-5 / 102 & 23 / 153 & -1 / 306 \\
-1 / 102 & -1 / 306 & 5 / 153
\end{array}\right]
\end{gathered}
$$

Corollary 3.3 Let $S=\left\{\mathrm{x}_{1}, \mathrm{x}_{2}, \ldots \ldots \ldots . \mathrm{x}_{\mathrm{n}}\right\}$ be an a-set, where $f(a) \neq 0$ and $f\left(x_{k}\right) \neq f(a)$ for

all $k=2, \ldots \ldots$, n. If $a \in S$ (i.e. $\left.a=x_{1}\right)$, then $(S)_{f}$ is invertible and

$$
\begin{aligned}
& \left(\left(S_{f}\right)^{-1}\right)_{i j}= \\
& \left\{\begin{array}{lr}
\frac{1}{f(a)}+\sum_{k=2}^{n} \frac{1}{f\left(x_{k}\right)-f(a)} & \text { if } i=j=1, \\
\frac{1}{f\left(x_{k}\right)-f(a)} & \text { if } 1<i=j, \\
\frac{1}{f(a)-f\left(x_{k}\right)} & \text { if } 1=i<j=k \text { or } 1=j<i=k \\
0 & \text { otherwise }
\end{array}\right.
\end{aligned}
$$

If $a \notin S$ and further $f\left(x_{1}\right) \neq f(a)$ and

$\frac{1}{f(a)} \neq \sum_{k=1}^{n} \frac{1}{f\left(x_{k}\right)-f(a)}$, then $(S)_{f} \quad$ is invertible and

$$
\begin{aligned}
& \left(\left(S_{f}\right)^{-1}\right)_{i j}= \\
& \left\{\begin{array}{r}
\frac{1}{f\left(x_{k}\right)-f(a)}-\frac{1}{\left[f\left(x_{k}\right)-f(a)\right]^{2}}\left(\frac{1}{f(a)}+\sum_{k=1}^{n} \frac{1}{f\left(x_{k}\right)-f(a)}\right)^{-1} \\
\text { if } i=j, \\
\frac{1}{\left[f\left(x_{k}\right)-f(a)\right]\left[f\left(x_{k}\right)-f(a)\right]}\left(\frac{1}{f(a)}+\sum_{k=1}^{n} \frac{1}{f\left(x_{k}\right)-f(a)}\right)^{-1} \\
\text { if } i \neq j .
\end{array}\right.
\end{aligned}
$$

\section{CONCLUSION}

The Mersenne Meet matrices on A sets is defined and the proof of the structure theorem is shown by example. The determinant and inverse of the Mersenne meet matrices on A sets are calculated through the results based on A sets. In future the various matrices similar to Mersenne matrix may be considered under this study.

\section{REFERENCES}

[1] P. Haukkanen, "On meet matrices on posets", LinearAlgebra Appl. 249: 111-123,1996.

[2] B. V. Rajarama Bhat, "On greatest common divisormatrices and their applications", Linear Algebra Appl.158: 77-97,1991.

[3] B. Wang, "Explicit Expressions of Smith's Determinanton a Poset", Acta Math Sin.(Engl. Ser.), 17(1): 161-168,2001.

[4] I. Korkee and P. Haukkanen, "Bounds for determinants ofmeet matrices associated with incidence functions",Linear Algebra Appl. 329(1-3): $77-88,2001$.

[5] I. Korkee and P. Haukkanen, "On meet matrices withrespect to reduced, extended and exchanged sets", JP J.Algebra Number Theory Appl., $4(3), 559-575,2004$.

[6] I. Korkee, "On meet and join matrices on $A$-sets andRelated Sets", Notes on Number theory and DiscreteMathematics, 10(3):57-67,2004.

[7] S. Beslin and S. Ligh, "GCD-closed sets and thedeterminants of GCD matrices", Fibonacci Quart.,30: 157-160,1992.

[8] P. Haukkanen, J.Wang and J. SillanpÄaÄa, "On Smith'sDeterminant", Linear Algebra Appl 258: 251-269, 1997.

[9] [P. Haukkanen and J. SillanpÄaÄa, "Some analogues ofSmith's determinant", Linear an Multilinear Algebra41: 233-244,1996.

[10] I. Korkee and P. Haukkanen, "On meet and join matricesassociated with incidence functions". Linear AlgebraAppl., 372: 127-153 , 2003.

[11] M. Aigner, “Combinatorial Theory”. Springer-Verlag,1979.

[12] G. Birkhof, "Lattice Theory". American MathematicalSociety Colloquium Publication, 25, Rhode Island, 1984.

[13] R. A. Horn, C. R. Johnson, "Matrix Analysis", CambridgeUniversity Press, New York , 1985.

[14] I. Korkee, " A note on meet and join matrices and theirspecial cases GCUD and LCUM Matrices", Int. J. Pure Appl. Math.1-11

[15] F. Zhang, "Matrix theory". Basic results and techniques, Universitext, Springer-Verlag, New York, 1999.

[16] Parthajit Roy, Swati Adhikari and J. K. Mandal, "AShortest Path Similarity Matrix based Spectral Clustering", International Journal of ComputerSciences and Engineering 4(1), 2015.

\section{AUTHORS PROFILE}

Elumalai. $\mathrm{N}$ serves as a Professor in Mathematics in A.V.C College, affiliated to Bharathidasan University. He has 29 years of experience in teaching and research in the field of Mathematics. He secured his Master and Master of Philosophy degrees from Madras University and Ph.D., from Government Arts College, Kumbakonam. He has published research papers in reputed national and international journals. He is presently guiding M.Phil., and Ph.D., scholars and produced M.Phil scholars.

Kalpana. $\mathrm{R}$ is presently working as an Assistant Professor in Saradha Gangadharan College, Puducherry. She has about 14 years of teaching experiences. She earned her Bachelor, Master and Master of Philosophy degrees in the field of Mathematics from Bharathidasan University. She has qualified SET-UGC both in Andhra Pradesh and Tamil Nadu. She has published a research paper and at present she is pursuing her research programme leading to Ph.D., degree in the field of Matrices. 